\title{
Burnout among nurses working in COVID-19 pandemic
}

\author{
Tri Ismu Pujiyanto ${ }^{1}$, Fery Agusman Motuho Mendrofa ${ }^{2}$, Umi Hani ${ }^{2}$ \\ ${ }^{1}$ Department of Nursing Management, Faculty of Nursing and Health Science, University of Karya Husada Semarang, Semarang, \\ Indonesia \\ ${ }^{2}$ Department of Community Health Nursing, Faculty of Nursing and Health Science, University of Karya Husada Semarang, Semarang, \\ Indonesia
}

\begin{tabular}{l} 
Article Info \\
\hline Article history: \\
Received Aug 26, 2021 \\
Revised Nov 20, 2021 \\
Accepted Dec 2, 2021 \\
\hline
\end{tabular}

Keywords:

Coping

Coronavirus

Isolated patients

\begin{abstract}
Nurses are at high risk of burnout because of the characteristic of their work that expends most of the time in delivering care to the patients. This study aimed to describe burnout among nurses working during corona virus disease 2019 (COVID-19) using nurses' demographic characteristics. This observational cross-sectional study involved 149 nurses from some hospitals and public health centers in Semarang using an online questionnaire from May 1 to June 15, 2020. Primary data were collected using Maslach Burnout Inventory including emotional exhaustion, depersonalization, and reduced personal accomplishment. Univariate and multivariate analyses were performed. The study showed that $63.6 \%$ of nurses in the COVID-19 unit were at high levels of emotional exhaustion, $56.3 \%$ of them were at high levels of depersonalization, and $46.7 \%$ of them are at high levels of reduced personal accomplishment. Education was the only demographic factor that was significantly related to emotional exhaustion and depersonalization $(p<0.05)$ with a weak correlation. The work environment and the reduced anxiety-related factors were not significantly correlated with the reduced personal accomplishment with a very weak correlation, while the nurses' unit was significantly correlated with depersonalization $(p<0.05)$ with a very weak correlation. The results found that burnout develops among nurses due to the work environment-related factors such as the unit of work, coronainfected patients, personal protective equipment usage, and the specific characteristics of the workplace. Nurses' characteristics affect their ability to manage the workload even in a pandemic. Nurses need optimal supports to build their self-efficacy. The organizational efforts play an important role in strengthening nurses to prevent burnout.
\end{abstract}

This is an open access article under the CC BY-SA license.

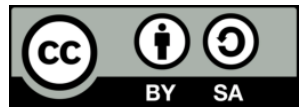

\section{Corresponding Author:}

Fery AM Mendrofa

Department of Community Health Nursing, Faculty of Nursing and Health Science, University of Karya Husada Semarang

Jl. R. Soekanto No.46, Sambiroto, Tembalang, Semarang City, Indonesia

Email: fery.mendrofa21@gmail.com

\section{INTRODUCTION}

Corona virus disease 2019 (COVID-19) is a newly emerging infectious disease that is a highly contagious viral pandemic affecting more than 12 million people in 216 countries around the world (as of July 14, 2020). It was announced as a community health emergency of international concern by world health organization (WHO) on January 30, 2020, and as a pandemic on March 11, 2020, and is declared by President of Indonesia as National Disaster on April 13th, 2020. The Health Ministry of Indonesia announced the total number of infections nationwide is 78,572. [1]-[4]. 
COVID-19 manifests clinically with symptoms that are recovery within a few weeks. The reported mild symptoms are fever, body aches, headache, cough, fatigue, and dyspnea. No specific antiviral treatment has been developed for its prevention. Health care professionals including doctors, nurses, and midwives, are playing an important role to combat, prevent, and manage patients with COVID-19 throughout the world [4]. Multiple reports of infection and fatalities of nurses which are of grave concern have surfaced in the pandemic. According to the Indonesian National Nurses Association (INNA), 20 nurses nationwide have died of COVID19 when they were on duty. However, nurses who are off duty might also get infected so the actual number of nurses who died of this virus might be higher than the official record. Thus, reports of nurses' mortality based on published reports are urgently required to overcome the challenges faced by nurses [5].

In an outbreak response, nurses are often at the forefront. Indeed, they have several roles in the management of a pandemic. Nurses face various challenges in the management of emerging infectious disease (EID) related to the raised but unpredictable risk of infection. Nurses experience some changes within their work environment and an uncertainty that become main barriers and being a challenge in nursing practice [6].

Nurses experience a high emotional stress within their work. Nurses describe the physical exhaustion and mental distress related to the strain of triage decisions, the infection risk, and also the pain of losing colleagues and their patients, bring nurses into vulnerable situation [7]. One prior study stated that nurses taking care for patients with infectious diseases, such as severe acute respiratory syndrome (SARS) and COVID-19, experienced mental and psychological distress [8]-[10]. In Saudi Arabia, 91.8\% of healthcare workers, most of them were nurses, had a negative attitude in treating patients with either suspected or confirmed middle east respiratory syndrome (MERS) [9], [11].

Nurses' anxiety and stress levels increased as the reports of COVID-19-related deaths. This is especially the case with forced deployments and deliveries to other frontline areas due to labor shortages. In addition, if a health worker involved in handling a case is infected or dies, it is more likely that the officer will avoid the suspected case or refuse to treat the patient [9], [12]. The study about the outbreak of SARS resulted that the nurses were desire to leave their jobs during the outbreak due to the perceived risk of work stress related to tanure, social relation, and fatality as well [9]. Another research has found that the negative side of work environment are related to increasing the risk of malicious consequences, specifically burnout and the impact toward the low-quality of care [13]. Burnout syndromes indicate a set of symptoms of exhaustion, expressed by a lack of physical depersonalization (DP) and self-devaluation reduced personal accomplishment (RPA). The impacts of burnout syndrome among nurses make detrimental effects to both individuals and organizations because a decline in one's biopsychosocial health leads to work dissatisfaction, absence and presence, and early retirement, which is turn harm the safety of patients [14], [15].

Nurses as health professionals are vulnerable to experiencing burnout the characteristics of their work are prolonged contact with the patients, expose to a high workload, terminated ill patients that they treated, and inappropriate training for workplace urgency, and emotional exhaustion [14], [15]. The 24 hours responsibility in caring for their patients may expose nurses to stress. It causes burnout in the long term care and interrupts the quality of care and their professional development [14], [16]. A worldwide COVID-19 pandemic is an unknown traumatic case for nurses, so there has been little research inspecting burnout related to COVID-19. Indeed, identifying the variables which are related to burnout syndrome is effective to prevent this syndrome [14]. Given this consideration, this study aimed to identify nurses' burnout levels during the COVID-19 pandemic and to describe the socio-demographic and work environment-related factors to disseminate basic information to lower and prevent the burnout among nurses.

\section{RESEARCH METHOD}

\subsection{Respondent}

This was a cross-sectional study with online questionnaire survey undertook from May 1 to June 15, 2020. The convenient sample was recruited through a public announcement and personal network that contains an invitation of participating in the burnout syndrome survey. The survey was composed of 184 nurses from some hospitals and public health centers in Semarang City, Indonesia. For inclusion, the respondents had to be nurses and providing direct care to patients during the COVID-19 pandemic in a hospital, public health center, or other health care services in Semarang City. Those who were on leave during the pandemic for any reason were excluded from this study.

This study was approved by the University of Karya Husada Semarang Ethics Board. The study was declared to have passed the ethical review by the Research Ethics Committee of University of Karya Husada Semarang No. 717/KH.KEPK/KT/III/2020. The study's purpose and contents were introduced before respondents enter the study. They fulfilled the questions after they were fully instructed and acknowledged the anonymity and other ethical considerations. This consent was not electronically recorded. All respondents agreed to the study through their contribution to this online survey on their own willingness. 


\subsection{Instrument}

This study used the maslach burnout inventory (MBI) and a passage of demographic details. The MBI consists of validated 22-item that leads measure of burnout through the workplace. The level of burnout is low, moderate, or high using the three domains of emotional exhaustion (EE), depersonalization (DP), and reduced personal accomplishment (RPA). The EE domain means loss of enthusiasm for work and about feelings of being emotionally overextended and exhausted, DP domain means increased cynicism and decreased empathy related to the impersonal response towards patients care, and RPA domain means feelings of inefficacious (low professional realization). A demographic survey captured age, gender, marital status, education, and years of work experience. Some questions regarding the work environment included workplace (intensive care unit, dialysis unit, surgical ward, emergency room, and others), COVID-19 patients in charge, and personal protective equipment (PPE) usage.

\subsection{Data analysis}

The respondents' characteristics were calculated for basic descriptive statistics. Means and SDs were calculated for continuous variables, while frequencies and percentages were generated for categorical variables. The correlations were analyzed using Spearmen Rank Correlation test to assess whether any correlation among demographic and work environment-related factors with burnout syndrome domains. All analyses were computed using IBM SPSS Version 23.

\section{RESULTS AND DISCUSSION}

\subsection{Results}

\subsubsection{Characteristics of respondents}

A total of 149 surveys were submitted. Table 1 provides participant baseline characteristics, along with the MBI scale results. The analyses used descriptive statistics of the burnout level presented in Table 2.

Table 1. Demographic and occupational characteristics of the respondents

\begin{tabular}{|c|c|c|}
\hline Socio-demographic characteristics & $\begin{array}{c}\text { Total } \\
\text { number }\end{array}$ & $(\mathrm{n}=149) \%$ \\
\hline \multicolumn{3}{|l|}{ Gender } \\
\hline Men & 47 & 31.5 \\
\hline Women & 102 & 68.5 \\
\hline \multicolumn{3}{|l|}{ Age } \\
\hline $21-30$ & 42 & 28.2 \\
\hline $31-40$ & 72 & 48.3 \\
\hline $41-50$ & 29 & 19.5 \\
\hline$>50$ & 6 & 4.0 \\
\hline \multicolumn{3}{|l|}{ Marital status } \\
\hline Married & 124 & 83.2 \\
\hline Single & 21 & 14.1 \\
\hline Widow/Widowed/Divorced & 3 & 2.0 \\
\hline \multicolumn{3}{|l|}{ Education } \\
\hline Vocational (Diploma degree) & 63 & 42.3 \\
\hline Professional (Bachelor degree) & 81 & 54.4 \\
\hline Advanced (Master degree at least) & 5 & 3.4 \\
\hline \multicolumn{3}{|l|}{ Work experience as a nurse } \\
\hline $1-5$ years & 33 & 22.1 \\
\hline $6-10$ years & 39 & 26.2 \\
\hline$>10$ years & 77 & 51.7 \\
\hline \multicolumn{3}{|l|}{ Unit of duty } \\
\hline Intensive care unit (ICU) & 19 & 12.8 \\
\hline Dialysis unit & 2 & 1.3 \\
\hline Emergency room (ER) & 10 & 6.7 \\
\hline Outpatient ward & 7 & 4.7 \\
\hline Inpatient ward & 71 & 47.7 \\
\hline Surgical ward & 10 & 6.7 \\
\hline Public health center (PHC) & 24 & 16.1 \\
\hline Others & 6 & 4.0 \\
\hline \multicolumn{3}{|l|}{ Caring for COVID-19 patients } \\
\hline On duty & 83 & 55.7 \\
\hline Done from duty & 14 & 9.4 \\
\hline Never & 52 & 34.9 \\
\hline \multicolumn{3}{|l|}{ Protective personal equipments (PPE) } \\
\hline Nurses used appropriate PPE & 128 & 85.9 \\
\hline Nurses who were less anxious with the use of PPE & 143 & 96 \\
\hline
\end{tabular}


Table 2. Level of burnout among nurses in pandemic situation $(n=149)$

\begin{tabular}{cccccccc}
\hline & $\begin{array}{c}\text { Emotional exhaustion } \\
\text { (EE) }\end{array}$ & \multicolumn{2}{c}{$\begin{array}{c}\text { Depersonalization } \\
\text { (DP) }\end{array}$} & \multicolumn{2}{c}{ Reduced personal accomplishment (RPA) } \\
Level & Total number & $\%$ & Total number & $\%$ & Total number & $\%$ \\
\hline High & 22 & 14.8 & 32 & 21.5 & 30 & 85 \\
Moderate & 104 & 69.8 & 95 & 63.8 & 34 & 22.1 \\
Low & 23 & 15.4 & 22 & 14.8 & & 22.8 \\
*Low, Moderate and high score are in accordance to cut-off scores
\end{tabular}

Our analysis shows that the prevalence of high levels of EE is $14.8 \%$ which was experienced more by female nurses $(15.7 \%)$ than males $(12.8 \%)$, and most of them were 21-30 years aged $(21.4 \%)$ and unmarried (19\%). $23.8 \%$ of vocational-educated nurses experience a high level of EE and $21.2 \%$ had less than five years of work experience. The cross-tabulation analysis between burnout level and work environment-related factors showed that $63.6 \%$ of nurses with high levels of EE were nurses in charge of the COVID-19 patients, $9.1 \%$ done the duty in caring COVID-19 patients, and 27.3\% has never been assigned in COVID-19 patients. In other analysis, related to the nurses' room, nurses with the high level of EE consecutively are public health nurses $(20.8 \%)$, surgical ward nurses (20\%), nurses in other areas (chemotherapy unit, COVID-19 isolation, transport, and homecare: 15.8\%), inpatient ward nurses (14.1\%), and emergency nurses (10\%). Although majority nurses using appropriate personal protective equipment, $15.6 \%$ of them were in the high level of EE.

Although $85.9 \%$ of nurses using appropriate personal protective equipment, $15.6 \%$ of them were in a high level of EE. 96\% of nurses felt secure while using PPE but $70.6 \%$ of them were at a moderate level of EE. The $4 \%$ of nurses felt anxious although they used PPE and $33.3 \%$ of them were in the high level of EE. Otherwise, the high score of DP and RPA was experienced more by male than female nurses (male: DP: 27.7\%, PA: $25.5 \%$; female: DP: $18.6 \%$, PA: $17.6 \%$ ), and most of them who had the high score of DP were more than 50 years aged $(33.3 \%)$ and had married $(23.4 \%)$. As a result in EE, most of the vocationaleducated nurses were in the high level of DP and RPA.

The cross-tabulation analysis between burnout level and work environment-related factors showed that $56.3 \%$ of nurses with a high level of DP were nurses in charge of the COVID-19 patients, $6.3 \%$ done the duty in caring COVID-19 patients, and 37.5\% has never been assigned in COVID-19 patients. The prevalence of high levels of DP is $21.5 \%$ which $56.3 \%$ of them are caring for COVID-19 patients. Nurses with this level consecutively are surgical ward nurse (40\%), nurses in other areas (chemotherapy unit, COVID-19 isolation, transport and homecare: 33.3\%), public health nurses (29.2\%), emergency nurses (20\%), inpatient ward nurses (18.3\%), ICU (15.8\%), and outpatient ward nurses (14.3\%). Although majority nurses using appropriate personal protective equipment, most of them were on a moderate level of DP $(64.8 \%)$.

The $20.1 \%$ of respondents were in high levels of RPA, which $46.7 \%$ of them are caring for COVID-19 patients. Nurses with this level consecutively are dialysis nurses (50\%), outpatient ward nurses (42.9\%), surgical ward nurse (40\%), nurses in other areas (chemotherapy unit, COVID-19 isolation, transport, and homecare: $33.3 \%)$, public health nurses (25\%), emergency nurses (20\%), ICU (15.8\%), and inpatient ward nurses (12.7\%).

\subsubsection{The relations between the burnout syndrome and the demographic factors}

The model summary table shows that the demographic factors (age, marital status, gender, education, and years of work experience) had a significant moderate effect only on EE (R: 0.330, $\mathrm{p}<0.05)$. Table 3 shows effect of demographic and work environment-related factors to burnout.

Table 3. Effect of demographic and work environment-related factors to burnout

\begin{tabular}{ccccccc}
\hline & \multicolumn{3}{c}{ Demographic factors } & \multicolumn{3}{c}{ Work environment-related factors } \\
Model & R & R square & Sig. F change & R & R square & Sig. F change \\
\hline EE & $.330^{\mathrm{a}}$ & .109 & .006 & $.100^{\mathrm{a}}$ & .010 & .689 \\
DP & $.262^{\mathrm{a}}$ & .068 & .071 & $.191^{\mathrm{a}}$ & .037 & .144 \\
RPA & $.205^{\mathrm{a}}$ & .042 & .289 & $.134^{\mathrm{a}}$ & .018 & .449
\end{tabular}

*Predictors: (Constant), age, gender, education level, marital status, years of work experience,

***Predictors: (Constant), PPE-anxiety reduction, personal protective equipment, unit of work, COVID-19 in charge

Correlations table showed that education was the only one demographic factor that significantly related to the three domains of burnout syndrome $(\mathrm{p}<0.05)$ with moderate correlation (correlation coefficient: 0.304 for EE dependent, 0.217 for DP dependent, and 0.193 for RPA dependent). Work environment-related factors included COVID-19 on charged and reduced anxiety-related PPE usage was not significantly 
correlated with the personal accomplishment (PA) domains of burnout with very weak correlation (correlation coefficient EE: 0.134, PA: 0.100). The unit where the nurses were on duty was significantly correlated with the DP domain $(\mathrm{p}<0.05)$ with a very weak correlation (correlation coefficient: 0.190$)$. Respondents were assured data would not be shared and remain confidential because of the sensitive nature of the questions used in this study as shown in Table 4.

Table 4. Correlation between demographic and work environment-related factors with burnout

\begin{tabular}{|c|c|c|c|c|c|}
\hline & & & $\mathrm{EE}$ & $\mathrm{DP}$ & RPA \\
\hline \multirow[t]{10}{*}{ Demographic factors } & \multirow{2}{*}{ Age } & Correlation Coefficient & 0.121 & -0.057 & -0.004 \\
\hline & & Sig. (2-tailed) & 0.141 & 0.491 & 0.962 \\
\hline & \multirow{2}{*}{ Gender } & Correlation Coefficient & -.044 & .025 & 0.071 \\
\hline & & Sig. (2-tailed) & .592 & .760 & .388 \\
\hline & \multirow{2}{*}{ Marital status } & Correlation Coefficient & -.038 & .081 & .028 \\
\hline & & Sig. (2-tailed) & .647 & .326 & .732 \\
\hline & \multirow{2}{*}{ Education } & Correlation Coefficient & $.304^{* *}$ & $.217^{* *}$ & $.193^{*}$ \\
\hline & & Sig. (2-tailed) & .000 & .008 & .018 \\
\hline & \multirow{2}{*}{ Work experience } & Correlation Coefficient & .051 & -.113 & .006 \\
\hline & & Sig. (2-tailed) & .534 & .171 & .944 \\
\hline \multirow{8}{*}{$\begin{array}{l}\text { Environment-related } \\
\text { factors }\end{array}$} & \multirow{2}{*}{ Unit of work } & Correlation Coefficient & -.008 & $-.190^{*}$ & -.062 \\
\hline & & Sig. (2-tailed) & .919 & .020 & .455 \\
\hline & \multirow{2}{*}{ Treated patients } & Correlation Coefficient & .105 & -.027 & -.021 \\
\hline & & Sig. (2-tailed) & .204 & .748 & .801 \\
\hline & \multirow{2}{*}{ Personal protective equipment usage } & Correlation Coefficient & .041 & .117 & .103 \\
\hline & & Sig. (2-tailed) & .624 & .155 & .212 \\
\hline & \multirow{2}{*}{$\begin{array}{l}\text { Nurses who were less anxious with the use of } \\
\text { PPE }\end{array}$} & Correlation Coefficient & .064 & .031 & -.095 \\
\hline & & Sig. (2-tailed) & .436 & .706 & .248 \\
\hline
\end{tabular}

**Correlation is significant at the 0.01 level (2-tailed)

*Correlation is significant at the 0.05 level (2-tailed).

\subsection{Discussion}

This study proposes to describe the level of burnout, and the related factors in nurses who take their responsibility in caring for patients during the COVID-19 pandemic, as no previous study has been established regarding this respect. The study showed that nurses working in the COVID-19 pandemic experience burnout in its three domains. The burnout syndrome is identified as a three-domains syndrome involving EE that expressed a lack of physical and mental energy, DP that implies lack of interest or cynical in work and negative thoughts about patients and the healthcare workers, and a low degree of personal accomplishment RPA regarding the own work engaged [17], [18].

This study showed that most nurses experience a moderate level in three domains of burnout. Healthcare professional is at high risk of exposure from infectious viruses, such as COVID-19, while treating patients. These risks are encountered by nurses during the nursing assessment process, at the beginning of a pandemic, and when took caring for an abundant number of patients. Nurses are vulnerably exposed to these risks due to their roles at the front desk of respond to patients and have a high level of distress [9], [19]. In this case, job stress has been a dominant factor in developing burnout. Nurses need to perform their work with certain expertise and professionalism when the level of stress increases, especially, during the pandemic and a newly emerging infectious disease. Therefore, effort and preparations for the outbreak of emerging contagious diseases should be made to reduce burnout [19]-[21]. This occasional fatigue and stress leads to burnout impact the poor quality of patient care, and may trigger malpractice as a consequence. The nursing professionals' excessive workload experienced by nurses during the pandemic is a factor for the poor quality of professional care [22]. The high EE, DP, and RPA imply the neglect of nurses in attempting to overcome the negative consequences of this syndrome. These domains of burnout impact negative attitudes towards their performance [21].

The burnout develops among nurses due to many possible risk factors. The sociodemographic such as age, gender, marital status, education degree, and work experience may contribute the psychological aspects such as personal character, restlessness, stress, or depression [21]. Nurses work in a context of work overload due to the accumulation of tasks, multiple technologies, continuous and shift work, deal very closely with the suffering of patients and death that build attachment with patients, and are constantly exposed to the risk of infection. Thus, the psychological and emotional aspects of nurses may affect the quality of nursing professionals [22].

The present study showed that the high level of EE is experienced more by female nurses than males. Most of the nurses with a high level of EE are 21-30 years aged (21.4\%) and unmarried (19\%). Other studies report that individuals like these characters are contributed to burnout syndrome. It is the double burden that comprises workload from time dedicated at a paid job and time spent at home and for recreation as well [17], [23]. The correlation between burnout an degree of education level is still controversial. The 
higher degree of education has been reported to impact the higher level of burnout. In other study, higher education level decreased burnout and did not correlated with burnout [24], [25]. Also in the present study, education was the only one demographic factor that significantly related to the three domains of burnout syndrome. Unfortunately, the present study does not identify the cause-and-effect correlation. Diplomaeducated nurses are the most of who experience a high level of EE (23.8\%). EE is significantly associated with education level. The present study shows a positive correlation between these variables implies the higher level of education, the higher EE they are [26].

Higher education for nurses may contribute to the better health care. They communicate better, and have depth critical thinking so they are able to deliver a holistic and evidence-based nursing care, that are required to fulfilling patients' needs and attain the high-quality of service [27], [28]. The nurses' self-efficacy that builds their confidence in delivering health care can prevent burnout among nurses. Yet, low educated nurses also experience burnout because they did significantly more assignments than did those with a bachelor degree of nurses in all clinical duties. But the bachelor nurses have more assignments in clinical tasks, while the master or specialist nurses responsible for more tasks in the management of nursing care. This may impact the lack of energy or feel depleted and a lack of occupational motivation and being heavy workload for nurses. Also, the factor of emotional nurses in running nursing services can affect performance in nursing service [29], [30].

Besides, EE seemed to increase in nurses with professional experience less than five years [15]. Work experience may decrease burnout because the more experience they have, the more confidence they are [24]. Nurses who have more experiences have better problems solving ability regarding the workplace with higher efficacy and certainty. They also may have developed a pleasant relationships at work [24].

Other studies also found that women are at higher risk of burnout than men due to the risk of DP that is getting worse by women's greater role in care. Women are also play double role as mother and nurse [15], [31]. Otherwise, the high score of DP and RPA was experienced more by male than female nurses and had married (23.4\%). Most of them who had high score of DP more than 50 years aged (33.3\%) and more than five years of professional experience $(24.7 \%)$. Male nurses of the this studies have a greater tendency to perform negative behaviors in delivering their nursing care and poor communicating with their team at the workplace [15]. Some studies stated that the family environment of a lifestyle provides convenience and support that prevents them from those negative behaviors [15], [32].

The work environment-related factors, including the unit of work, COVID-19-related patients in charge, personal protective equipment (PPE) usage, and reduced anxiety-related PPE usage, are also important to be considered. Furthermore, the certain characteristics of the workplace also contribute in developing burnout among nurses. Therefore, the characteristic of patient, the workload at the workplace, and nurses' family are contribute to the appearance of burnout [21]. The burnout syndrome of nurses can be triggered by a poor management of human resources and supplies to provide quality of care to patients. It results in the poor delivery performance of care [22].

Regarding the work environment-related factors, another study described four components consist of autonomy, control over the environment, physician-nurse relationship, and organizational support. Indeed, individual vulnerability and the professional environment, including the daily workplace and the community, impact the burnout among nurses. Burnout is also particularly determined by the poor organization of work that causes work overload, lack of autonomy, and lack of support for nurses' duties [13].

The present study identifies the work environment-related factors including with COVID-19 infected patients' condition and reduced anxiety with PPE usage were not significantly correlated with the PA domains of burnout. The unit of works is the only one work environment-related factor that significantly correlated with DP domain $(\mathrm{p}<0.05)$ with a very weak correlation (correlation coefficient $=0.190)$. The other study also showed that task overload related to the unit of work was positively associated with burnout. Burnout among nurses correlates with the problems of work environment of nursing practice. These results cannot be the framework in burnout prevention among nurses due to many other variables that may control over the environment that correlated with the burnout domains [13]. The poor work environment is correlated to the risk of burnout among nurses and causes the low-quality of nursing care [13]. Regarding nurses who care for COVID-19 patients, 63.6\% of them experience a high level of EE and most of them are public health nurses $(20.8 \%), 56.3 \%$ of them experience a high level of DP and most of them are surgical ward nurse $(40 \%)$, while $46.7 \%$ of them experience a high level of PA and most of them are dialysis nurses (50\%).

Nurses working in an emerging situation vulnerably experience burnout. The high score of EE indicates the anxiety and stress experienced by nurses. Undesirable work conditions with limited time in performing nursing care and an overload of tasks may contribute to the high EE scores. COVID-19 as a new case gives nurses new conditions. Lack of experience for nurses in caring COVID 19 related patients can aggravate the high score of EE. The high level of EE identified among public health nurses related to the difficult of patients that they care. Public health centers provide their services in their own community and 
are held in a prolonged period [33], [34]. The importance of primary care in health services, and the increasing demand for public health services, sues nurses to face the new challenges and increasing more stressor to the work. Therefore, we must determine some factors that contribute to EE among nurses in their workplace such as delivering nursing care in their patients' homes, the overload of their tasks, or the lack of control over their own workplace.

Working conditions also increase the DP scores, specifically in dialysis nurses who routinely meet a chronic illness such as end-stage kidney disease that need long-term care. This occurs usually in a growing poor prognosis elderly who often require heavy physical efforts; even the high risk of death in the unit. Dialysis nurses are experienced to high levels of burden and stress [20], [34].The unit where the nurses were on duty was significantly correlated with the DP domain $(\mathrm{p}<0.05)$ with a very weak correlation. Professional activities should attain a satisfaction either in economic or professional. The professional task should emphasize the main role of nurses in community. However, different levels of job stress along the daily practice, may lead to the increasing level of burnout [13]. Nurses may experience burnout, have the resilience to stay in their work due to their optimism [25], [35].

Personal characteristics factors could be more associated with burnout among nurses during the pandemic than any work environment factors. A person's characteristics affect one's ability to overcome the workload even in the pandemic. Organizational efforts play an important role in strengthening nurses to prevent burnout. Nurses need to get maximum support to carry out their work with high self-efficacy and a feeling of security [22].

\section{CONCLUSION}

The factors of demographic and work environment are not the only variables that impact burnout among nurses in the pandemic. The other factor may contribute the burnout and challenged nurses. Nurses may neglect their personal and their duty in effort to overcome the negative consequences of this syndrome, increasing the negative attitudes towards their work. As stated above, the pandemic has a specific burden that distinguishes it from all others, whether the burnout characteristic the same as the normal situation. It means professionalism in nursing is required to deal with the COVID-19 pandemic.

These results imply that nurses' managers should determine several factors in nurses that more prone to burnout. Interventions to prevent and treat burnout are necessary for nurses and other health professional to promote better workplace wellbeing. The related organization should assess the required programs to increase the quality of care. Nursing professionals should understand the physical and emotional requirement, in an instant, support through the self-help groups to share their feeling or to request the burnout intervention. Nursing management should assess the future study to find the effective interventions in preventing the burnout among nurses, specifically during the pandemic. Handling burnout problems is seen as being able to improve the quality of patient care. Interventions that increase self-support to deal with the work environment are needed to help control this syndrome. However, interventions are more suggested at the readiness on duty in a routine workplace, the structure, and the functions that manage it than in the other factor related to burnout.

\section{ACKNOWLEDGMENTS}

This research was self-funded. Our appreciation goes to all nurses that participated in this study and our deepest appreciation goes to all nurses facing the COVID-19 pandemic. The authors have no conflicts of interest associated with this study.

\section{REFERENCES}

[1] Satgas Penanganan COVID-19, "Decree of the Minister of Health of the Republic of Indonesia Number Hk.01.07/Menkes/328/2020 concerning Guidelines for prevention and control of coronavirus disease 2019 (COVID-19) in the workplace, (In Indonesia: Keputusan Menteri Kesehatan Republik Indonesia Nomor Hk.01.07/Menkes/328/2020 Tentang Panduan Pencegahan Dan Pengendalian corona virus disease 2019 (COVID-19) di tempat kerja," Menteri Kesehat. Republik Indones., vol. 2019, pp. 1-207, 2020.

[2] S. Paybast, F. Baghalha, A. Emami, and M. Koosha, "The anxiety disorder among the healthcare providers during the covid-19 infection pandemic: a systematic review," International Clinical Neuroscience Journal, vol. 7, no. 3, pp. 115-121, 2020, doi: 10.34172/icnj.2020.11.

[3] K. C. Robbins, "NNJ Journal club - support for nurses during the Global COVID-19 pandemic," Nephrology Nursing Journal, vol. 47, no. 3, p. 271, 2020, doi: 10.37526/1526-744x.2020.47.3.271.

[4] A. Naseer, M. Shakoor, F. Vohra, T. Abduljabbar, Q. Mariam, and M. A. Rehman, "Knowledge, awareness and practice of health care professionals amid SARS-CoV-2, corona virus disease outbreak," Pakistan Journal of Medical Sciences, vol. 36, no. S4, May 2020.

[5] A. A. Parikesit, N. R. P. Ratnasari, and D. Anurogo, "Application of artificial intelligence-based computation in the health sciences to ward off the COVID-19 pandemic," International Journal Human Health Science, vol. 5, no. 2, pp. 177-184, 2020.

[6] S. K. K. Lam, E. W. Y. Kwong, M. S. Y. Hung, and C. Wai-tong, "Investigating the strategies adopted by emergency nurses to address uncertainty and change in the event of emerging infectious diseases: a grounded theory study," International Journal of 
Environmental Research and Public Health, vol. 17, no. 7, p. 2490, 2020, doi: 10.3390/ijerph17072490.

[7] The Lancet, "COVID-19: protecting health-care workers," Lancet (London, England), vol. 395, no. 10228, p. 922, Mar. 2020, doi: 10.1016/S0140-6736(20)30644-9.

[8] M.-C. Feng et al., "Exploring the stress, psychological distress, and stress-relief strategies of Taiwan nursing staffs facing the global outbreak of COVID-19," Hu Li Za Zhi, vol. 67, no. 3, pp. 64-74, 2020, doi: 10.6224/JN.202006_67(3).09.

[9] N. Oh, N. S. Hong, D. H. Ryu, S. G. Bae, S. Kam, and K. Y. Kim, "Exploring Nursing intention, stress, and professionalism in response to infectious disease emergencies: the experience of local public hospital nurses during the 2015 MERS outbreak in South Korea," Asian Nursing Research (Korean. Soc. Nurs. Sci)., vol. 11, no. 3, pp. 230-236, 2017, doi: 10.1016/j.anr.2017.08.005

[10] R. Fernandez et al., "Implications for COVID-19: A systematic review of nurses' experiences of working in acute care hospital settings during a respiratory pandemic," International Journal of Nursing Studies, vol. 111, p. 103637, 2020, doi: 10.1016/j.ijnurstu.2020.103637.

[11] M. AlJohani and A. AlQahtani, "Prevalence and risk factors of anxiety among Saudi male secondary schools' students in Madinah, Saudi Arabia," International Journal Medical Science Public Health, vol. 5, no. 5, pp. 994-999, 2016, doi: 10.5455/ijmsph.2016.10022016362.

[12] S. A. Boamah, H. K. S. Laschinger, C. Wong, and S. Clarke, "Effect of transformational leadership on job satisfaction and patient safety outcomes," Nursing Outlook, vol. 66, no. 2, pp. 180-189, 2018, doi: 10.1016/j.outlook.2017.10.004.

[13] L. de S. Nogueira, R. M. C. de Sousa, E. de S. Guedes, M. A. Dos Santos, R. N. T. Turrini, and D. de A. L. M. da Cruz, "Burnout and nursing work environment in public health institutions," Rev. Bras. Enferm., vol. 71, no. 2, pp. 336-342, 2018, doi: 10.1590/0034-7167-2016-0524.

[14] S. Grigorescu, A. M. Cazan, O. D. Grigorescu, and L. M. Rogozea, "The role of the personality traits and work characteristics in the prediction of the burnout syndrome among nurses - a new approach within predictive, preventive, and personalized medicine concept," EPMA J., vol. 9, no. 4, pp. 355-365, 2018, doi: 10.1007/s13167-018-0151-9.

[15] G. Cañadas-De la Fuente, E. Ortega, L. Ramirez-Baena, E. De la Fuente-Solana, C. Vargas, and J. Gómez-Urquiza, "Gender, marital status, and children as risk factors for burnout in nurses: a meta-analytic study," Int. J. Environ. Res. Public Health, vol. 15, no. 10, p. 2102, Sep. 2018, doi: 10.3390/ijerph15102102.

[16] A. Abbaszadeh, A. Elmi, F. Borhani, and R. Sefidkar, "The relationship between 'compassion fatigue' and 'burnout' among nurses," Ann. Trop. Med. Public Heal., vol. 10, no. 4, pp. 869-873, 2017, doi: 10.4103/ATMPH.ATMPH_234_17.

[17] V. Vidotti, J. T. Martins, M. J. Q. Galdino, R. P. Ribeiro, and M. L. do C. C. Robazzi, "Burnout syndrome, occupational stress and quality of life among nursing workers," Enferm. Glob., vol. 18, no. 3, pp. 344-354, 2019, doi: 10.6018/eglobal.18.3.325961.

[18] C. S. Monsalve-Reyes, C. San Luis-Costas, J. L. Gómez-Urquiza, L. Albendín-García, R. Aguayo, and G. A. Cañadas-De La Fuente, "Burnout syndrome and its prevalence in primary care nursing: a systematic review and meta-analysis," BMC Fam. Pract., vol. 19, no. 1, p. 59, 2018, doi: 10.1186/s12875-018-0748-z.

[19] L. Han et al., "Anxiety and depression of nurses in a North West Province in China during the period of novel coronavirus pneumonia outbreak," J. Nurs. Scholarsh., vol. 52, no. 5, pp. 564-573, Jul. 2020, doi: 10.1111/jnu.12590

[20] J. S. Kim and J. S. Choi, "Factors influencing emergency nurses' burnout during an outbreak of middle east respiratory syndrome coronavirus in Korea," Asian Nurs. Res. (Korean. Soc. Nurs. Sci)., vol. 10, no. 4, pp. 295-299, 2016, doi: 10.1016/j.anr.2016.10.002

[21] E. I. De La Fuente-Solana, N. Suleiman-Martos, L. Pradas-Hernández, J. L. Gomez-Urquiza, G. A. Cañadas-De La Fuente, and L. Albendín-García, "Prevalence, related factors, and levels of burnout syndrome among nurses working in gynecology and obstetrics services: A systematic review and meta-analysis," Int. J. Environ. Res. Public Health, vol. 16, no. 14, 2019, doi: 10.3390/ijerph16142585.

[22] C. C. F. M. Rodrigues, V. E. P. Santos, and P. Sousa, "Patient safety and nursing: interface with stress and burnout syndrome," Rev. Bras. Enferm., vol. 70, no. 5, pp. 1083-1088, 2017, doi: 10.1590/0034-7167-2016-0194.

[23] M. Iorga et al., "Factors influencing burnout syndrome in obstetrics and gynecology physicians," Biomed Res. Int., vol. 2017, p. 9318534, 2017, doi: 10.1155/2017/9318534.

[24] A. Karakoc, M. Yilmaz, N. Alcalar, B. Esen, H. Kayabasi, and D. Sit, "Burnout syndrome among hemodialysis and peritoneal dialysis nurses," Iran. J. Kidney Dis., vol. 10, no. 6, pp. 395-404, 2016.

[25] A. Mohammadpoorasl, A. Maleki, and M. H. Sahebihagh, "Prevalence of professional burnout and its related factors among nurses in Tabriz in 2010," Iran. J. Nurs. Midwifery Res., vol. 17, no. 7, pp. 524-529, Nov. 2012.

[26] L. C. de Paiva, A. C. G. Canário, E. L. C. de Paiva China, and A. K. Gonçalves, "Burnout syndrome in health-care professionals in a university hospital," Clinics, vol. 72. scielo, pp. 305-309, 2017

[27] X. Liu et al., "Associations of nurse education level and nurse staffing with patient experiences of hospital care: A cross sectional study in China," Res. Nurs. Health, vol. 43, no. 1, pp. 103-113, Feb. 2020, doi: 10.1002/nur.22003.

[28] American Association of Colleges of Nursing, "Fact sheet: The impact of education on nursing practice. Washington," 2019. https://www.aacnnursing.org/Portals/42/News/Factsheets/Education-Impact-Fact-Sheet.pdf (accessed 5 Jul 2021).

[29] T. I. Pujiyanto and S. Hapsari, "Performance enhancement of nurses with quality of nursing work life model," Int. J. Psychosoc. Rehabil., vol. 24, no. 7, pp. 7736-7743, 2020, doi: 10.37200/IJPR/V24I7/PR270744.

[30] M. Masfuri, A. Waluyo, Y. Afiyanti, and A. Y. S. Hamid, "Educational background and clinical nursing tasks performed by nurses in Indonesian hospitals," Enfermería Clínica, vol. 29, pp. 418-423, 2019, doi: 10.1016/j.enfcli.2019.04.061.

[31] M. Kavurmaci, I. Cantekin, and M. Tan, "Burnout levels of hemodialysis nurses," Ren. Fail., vol. 36, no. 7, pp. 1038-1042, Aug. 2014, doi: 10.3109/0886022X.2014.917559.

[32] G. A. Cañadas-De la Fuente, C. Vargas, C. San Luis, I. García, G. R. Cañadas, and E. I. De la Fuente, "Risk factors and prevalence of burnout syndrome in the nursing profession," Int. J. Nurs. Stud., vol. 52, no. 1, pp. 240-249, Jan. 2015, doi: 10.1016/j.ijnurstu.2014.07.001.

[33] A. Girard, C. Hudon, M. E. Poitras, P. Roberge, and M. C. Chouinard, "Primary care nursing activities with patients affected by physical chronic disease and common mental disorders: a qualitative descriptive study," J. Clin. Nurs., vol. 26, no. 9-10, pp. 1385-1394, May 2017, doi: 10.1111/jocn.13695.

[34] K. Rusca Putra, H. Sutadi, S. Setyowati, and R. T. S. Hayati, "The effect of caring work environment model on nurses' burnout in general hospitals," Int. J. Public Heal. Sci., vol. 10, no. 3, p. 537, 2021, doi: 10.11591/ijphs.v10i3.20800.

[35] E. B. Bunga, N. G. A. Eka, and E. O. Hutasoit, "Relationship between burnout and resilience of nurses at a private hospital in Indonesia," Enfermería Clínica, vol. 30, pp. 49-52, 2020, doi: 10.1016/j.enfcli.2019.12.025 